\title{
Carbonation of Epoxy Methyl Soyate at Atmospheric Pressure
}

\author{
Ronald Alan Holser* \\ NCAUR,USDA, ARS (1815 North University Street, Peoria, IL 61604 USA)
}

\begin{abstract}
Vegetable oils are important substrates for the development of biobased products that may replace products derived from petroleum. Carbonated methyl soyates were prepared at atmospheric pressures from epoxy methyl soyate by the introduction of carbon dioxide at the oxirane position. Carbonation was performed by sparging carbon dioxide gas through the neat epoxy esters at atmospheric pressure in the presence of tetrabutylammonium bromide catalyst. Analysis of reaction mixtures showed that $42 \%$ of the epoxide groups were carbonated after $18 \mathrm{~h}$ at $80^{\circ} \mathrm{C}$ with $1 \mathrm{wt} \%$ catalyst compared to $63 \%$ using liquid carbon dioxide at 54 atm pressure.
\end{abstract}

Key words: Carbonates, carbonation, methyl soyate, epoxidized methyl soyate, oxirane

\section{INTRODUCTION}

Short chain linear and cyclic organic carbonates are useful industrial solvents and intermediate chemicals that are commonly produced by the carbonation, carbonylation, phosgenation, or transesterification of alcohols ${ }^{1-4)}$. These reactions may involve hazardous co-reactants such as phosgene or generate side products. Alternatively, carbonates may be prepared by the addition of carbon dioxide directly to an epoxide without these concerns ${ }^{5-9)}$. This route also provides the benefit of chemically fixing carbon dioxide which is a by-product of many industrial processes and has been connected to the environmental topic of global warming. Carbon dioxide is nonflammable, inexpensive, and represents a potential carbon source for industrial synthesis.

In contrast to short chain organic carbonates like dimethyl and diethyl carbonate which are most often derived from petroleum feedstocks the long chain organic carbonates may be prepared from oleochemical substrates. While the long chain carbonates have not been utilized to the same extent as the short chain carbonates they are finding applications as components in lubricants, cosmetics, and plastics ${ }^{10)}$. The linear oleochemical carbonates exhibit physical properties similar to fatty esters and have been evaluated as potential fuel additives ${ }^{11}$. An advantage of carbonates in lubricant formulations is the production of non-corrosive degradation products such as fatty alcohols rather than the more corrosive free fatty acids that are obtained from the hydrolysis of an ester.

Cyclic carbonates may also be prepared by the carbonation of epoxidized oleochemical substrates. This synthetic route is of particular interest since it can use surplus carbon dioxide directly without generating side products as noted above. This scheme was applied to epoxidized soybean oil and shown to convert the oxirane to the carbonate with carbon dioxide at atmospheric pressures in the presence of tetrabutylammonium bromide ${ }^{12,13}$. Similarly, it was shown that epoxidized methyl oleate could be carbonated with supercritical carbon dioxide ${ }^{14)}$. The availability of epoxidized vegetable oils and the corresponding epoxidized esters suggests a ready supply of renewable substrates for the production of long chain cyclic carbonates. This study was undertaken to investigate the carbonation of epoxidized methyl soyate with carbon dioxide gas at atmospheric pressure. Carbonated methyl soyate represents a useful chemical intermediate for the synthesis of functional fluids, fuel additives, and other biobased products. It would be advantageous to perform the carbonation reactions at atmospheric pressure to avoid the requirement of high pressure equipment and the operating costs associated with supercritical or subcritical carbon dioxide processes. \footnotetext{
E-mail: ronald.holser@ars.usda.gov Accepted August 17, 2007 (received for review July 18, 2007)

Journal of Oleo Science ISSN 1345-8957 print / ISSN 1347-3352 online

http://jos.jstage.jst.go.jp/en/
}

* Correspondence to: Ronald Alan Holser, NCAUR,USDA, ARS, 1815 North University Street, Peoria, IL 61604 USA 


\section{R.A. Holser}

\section{EXPERIMENTAL}

\subsection{Materials}

Epoxidized soybean oil methyl esters were obtained from Arkema, Inc., (Blooming Prairie, $\mathrm{MN}$ ). $\mathrm{AlCl}_{3}$, LiBr, tetrabutylammonium bromide (TBAB), methanol, sodium methoxide, and bromoacetic acid were purchased from Sigma-Aldrich Chemicals, (St. Louis, MO). Carbon dioxide (99.9\% purity) was obtained from Linde Gas, LLC (Independence, $\mathrm{OH})$.

\subsection{Carbonation reactions}

Carbonation was performed at atmospheric pressure by placing $5 \mathrm{~g}$ portions of the epoxidized methyl soyate into a glass vial measuring $2 \mathrm{~cm} \times 20 \mathrm{~cm} . \mathrm{AlCl}_{3}, \mathrm{LiBr}$, or $\mathrm{TBAB}$ catalyst was added to the epoxidized esters at 1,5 , or 10 wt $\%$ levels and the vial was heated to 80,110 , or $120^{\circ} \mathrm{C} \pm$ $0.5^{\circ} \mathrm{C}$ in a block heater (Lab-line Instruments Inc., Melrose Park, IL). Carbon dioxide was sparged through the reaction mixture with a sintered glass tube at $5 \mathrm{~mL} / \mathrm{min}$. The reaction was continued for 24 hours with periodic sampling of small aliquots, $0.1 \mathrm{~mL}$, for analysis by FTIR and GC.

The carbonation of epoxidized methyl esters with liquid carbon dioxide was performed in a $50 \mathrm{~mL}$ pressure reactor (Parr Instrument Co., Moline, IL). The reactions used $5 \mathrm{~g}$ of epoxidized methyl esters and 1 or $5 \mathrm{wt} \%$ of $\mathrm{AlCl}_{3}$, $\mathrm{LiBr}$, or TBAB catalyst. These materials were placed into the reactor and the reactor was sealed and filled with carbon dioxide at $25 \mathrm{~atm}$. The reactor was heated to the reaction temperature, either $80^{\circ} \mathrm{C}$ or $120^{\circ} \mathrm{C}$, and the pressure was increased to $54 \mathrm{~atm}$ by the addition of carbon dioxide with a syringe pump. The reactions were stirred at $500 \mathrm{RPM}$ and maintained at the selected temperature for 4 , 8 , or 18 h. At the end of the reaction period the reactor was cooled to ambient temperature, vented, and opened for product analysis.

\subsection{Measurements}

\subsubsection{Infrared spectroscopy (IR)}

Infrared spectra were obtained with a Thermo Nicolet, Nexus FT-IR 470 spectrometer, using the diamond ATR accessory (Thermo Electron Corp., Palo Alto, CA). A drop of the neat reaction mixture was placed onto the crystal and the sample was scanned from $400-4000 \mathrm{~cm}^{-1}$. Spectral data were collected and processed by Omnilab software (Thermo Electron Corp., Palo Alto, CA). Strong absorption at $1800 \mathrm{~cm}^{-1}$ is characteristic of the carbonate structure and absorbances at 844 and $821 \mathrm{~cm}^{-1}$ attributable to oxirane oxygen.

2.3.2 Gas liquid chromatography

Samples were analyzed with the Agilent 6890 gas chromatograph using a flame ionization detector (GC-FID). Separations were performed with a DB-5HT column measuring $15 \mathrm{~m} \times 0.32 \mathrm{~mm} \times 0.1$ micron film thickness $(\mathrm{J} \& \mathrm{~W}$ Scientific, Folsom, CA). The carrier gas was helium flow- ing at $5 \mathrm{~mL} / \mathrm{min}$. The oven was programmed from an initial temperature of $50^{\circ} \mathrm{C}$ to $180^{\circ} \mathrm{C}$ at $15^{\circ} \mathrm{C} / \mathrm{min}$, increased to 230 at $7^{\circ} / \mathrm{min}$, and then to $380^{\circ} \mathrm{C}$ at $30^{\circ} \mathrm{C} / \mathrm{min}$ with a ten minute hold. Injection volumes were $1 \mu \mathrm{L}$ with the inlet set to splitless mode. Identification of eluents was made by comparison to the retention times of known standards. Data were collected and processed via Chemstation software (Agilent Technologies, Inc., Palo Alto, CA).

\subsubsection{Gas chromatography-mass spectrometry (GC-MS)}

Mass spectra were collected using the Agilent $6890 \mathrm{~N}$ gas chromatograph equipped with the 5973 mass selective detector operated in EI mode (Agilent Technologies, Inc., Palo Alto, CA). Separations were achieved using the HP$5 \mathrm{~ms}$ column, $30 \mathrm{~m} \times 0.25 \mathrm{~mm}$ ID $\times 0.25$ micron film thickness. Helium was used as the carrier gas with a linear velocity of $35 \mathrm{~cm} / \mathrm{sec}$. The oven temperature was programmed from $120^{\circ} \mathrm{C}$ to $240^{\circ} \mathrm{C}$ at $10^{\circ} \mathrm{C} / \mathrm{min}$ with an initial two minute hold and a final ten minute hold. The inlet was heated to $230^{\circ} \mathrm{C}$ and set for splitless injections with a one microliter injection volume. The detector source was heated to $230^{\circ} \mathrm{C}$ and the detector quadrapole was heated to $150^{\circ} \mathrm{C}$. Data were collected and processed via Chemstation software (Agilent Technologies, Inc., Palo Alto, CA). 2.3.4 Oxirane determinations.

Oxirane values were determined by titration following AOCS standard test method Cd 9-57 ${ }^{15)}$. Titrations were performed in triplicate with $0.3-0.5 \mathrm{~g}$ samples dissolved in $10 \mathrm{~mL}$ chlorobenzene/acetic acid $(2: 1)$ and titrated to the endpoint with $33 \% \mathrm{HBr}$ in acetic acid.

\section{RESULTS AND DISCUSSION}

\subsection{Analysis of carbonated products}

The addition of carbon dioxide to the oxirane group to form the cyclic carbonate was qualitatively followed by FTIR. The oxirane group exhibits two characteristic absorbance peaks at $844 \mathrm{~cm}^{-1}$ and $821 \mathrm{~cm}^{-1}$ while the carbonate absorbs strongly at $1800 \mathrm{~cm}^{-1}$. Figure 1 presents typical spectra for the carbonation reaction of epoxidized methyl soyate with carbon dioxide gas. Formation of the carbonate and disappearance of the epoxide structures were confirmed by GC-MS and GC-FID analyses. Titrations for oxirane oxygen were used to quantify the amount of unreacted epoxy groups.

\subsection{Catalyst activity}

Preliminary reactions were performed with $1 \mathrm{wt} \%$ of $\mathrm{AlCl}_{3}, \mathrm{LiBr}$, or TBAB in separate experiments to determine the most active of these catalysts for further investigation. Catalyst activities were determined from $4 \mathrm{~h}$ reactions of the epoxidized methyl soyate with liquid carbon dioxide at $54 \mathrm{~atm}$ and $120^{\circ} \mathrm{C}$. Analysis of products showed that oxirane values decreased from 6.3 to 5.9 with $\mathrm{AlCl}_{3}$ and to 4.2 


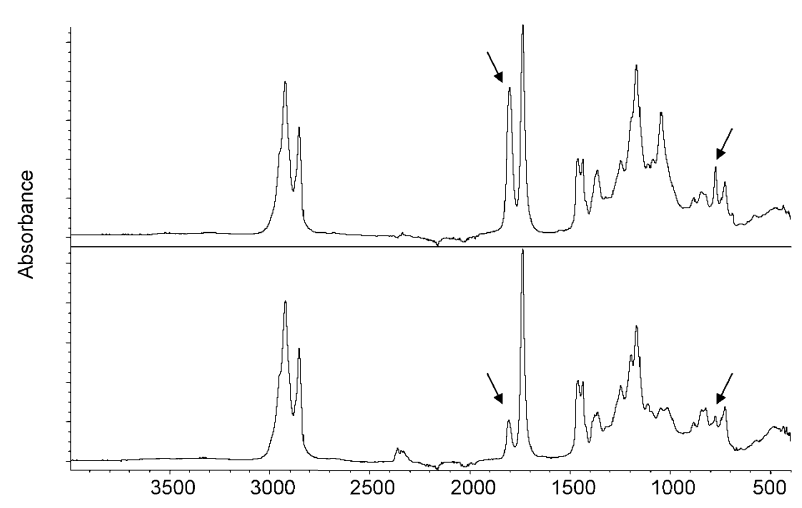

Fig. 1 FTIR spectra of epoxidized methyl soyate carbonation reaction after $2 \mathrm{~h}$ (bottom) and $18 \mathrm{~h}$ (top) with $5 \mathrm{wt} \% \mathrm{TBAB}$ catalyst at $120^{\circ} \mathrm{C}$ and atmospheric pressure. The decrease in absorbance of the oxirane group $\left(844 \mathrm{~cm}^{-1}, 821 \mathrm{~cm}^{-1}\right)$ and increase in carbonate absorbance $\left(1799 \mathrm{~cm}^{-1}\right)$ is noted.

with TBAB. There was no decrease in oxirane value for reactions with $\mathrm{LiBr}$ catalyst at these conditions. Based on these results TBAB was used as the catalyst for subsequent reactions.

\subsection{Effects of catalyst level, temperature, and pressure}

In a series of reactions performed with carbon dioxide gas the amount of TBAB was varied to study the influence of catalyst level on carbonation. Conversions of $15 \%, 46 \%$, and $49 \%$ were obtained with $1 \mathrm{wt} \%, 5 \mathrm{wt} \%$, and $10 \mathrm{wt} \%$ TBAB, respectively at $120^{\circ} \mathrm{C}$ after 24 hours. Increasing the amount of catalyst from $1 \mathrm{wt} \%$ to $5 \mathrm{wt} \%$ tripled the extent of reaction while $10 \mathrm{wt} \%$ catalyst produced only a slight additional increase. In other reactions the temperature dependence of the carbonation reaction was investigated with carbon dioxide gas and $5 \mathrm{wt} \%$ TBAB. The results plotted in Fig. 2 show a linear decrease in oxirane value with increasing temperature.

The role of pressure on the extent of the carbonation reaction was evaluated by comparing reactions conducted at $1 \mathrm{~atm}$ carbon dioxide with reactions at 54 atm carbon dioxide using $1 \mathrm{wt} \% \mathrm{TBAB}$ catalyst. At $120^{\circ} \mathrm{C}$ and $1 \mathrm{~atm}$ carbon dioxide $15 \%$ conversion of oxirane was obtained after 24 hours compared to 34\% and 63\% after 4 hours and 18 hours, respectively, at 54 atm pressure. However, when the temperature was reduced to $80^{\circ} \mathrm{C}$ conversions of $50 \%$ were obtained after 24 hours with 1 atm carbon dioxide. This interesting result was attributed to the temperature dependence of carbon dioxide solubility and the interphase mass transfer rates achieved in the reactant mixture. Additional reactions at these conditions showed similar conversions versus time with $12 \%$ obtained after 2 hours and $42 \%$ after 18 hours. This is in contrast to the pressur-

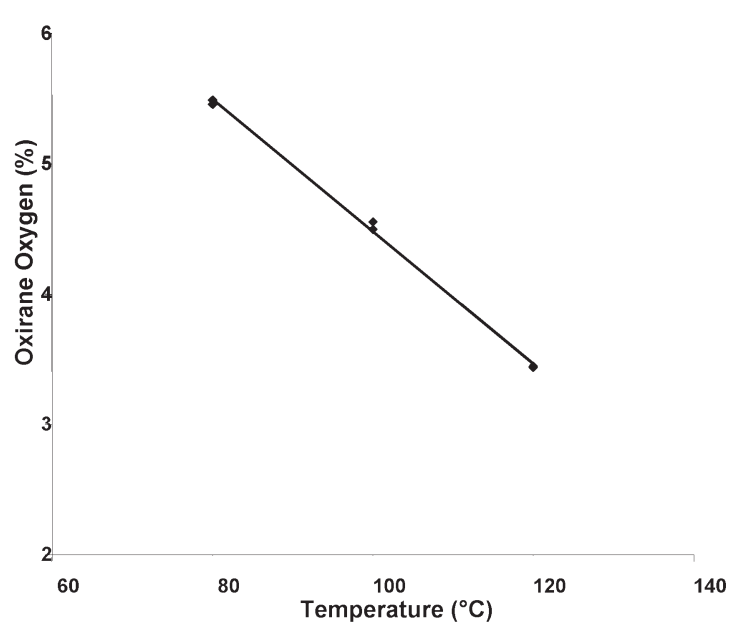

Fig. 2 Plot of oxirane oxygen values after $24 \mathrm{~h}$ reaction of epoxidized methyl soyate with carbon dioxide gas at atmospheric pressure and $5 \mathrm{wt} \%$ TBAB catalyst.

ized reactor system where the carbon dioxide remains confined and dispersed by the impeller into the reaction mixture. Higher rates of mass transfer are expected to prevail in the stirred reactor with reduced influence of temperature on solubility than in the sparged reactor.

\section{CONCLUSIONS}

These results demonstrated that the addition of carbon dioxide to epoxidized methyl soyate may be performed at atmospheric pressure to produce the carbonated product. The carbonation of the epoxide group proceeded more rapidly at higher carbon dioxide pressures and temperatures although lower reaction temperatures produced similar conversions at atmospheric pressure. The use of carbon dioxide gas at atmospheric pressure offers potential for an economical reaction process compared to the high pressure equipment and conditions required for reactions using liquid or supercritical carbon dioxide. It is expected that the carbonated products obtained from vegetable oil esters such as methyl soyate will replace petrochemicals for industrial applications.

\section{DISCLAIMER}

The use of trade, firm, or corporation names in this publication is for the information and convenience of the reader. Such use does not constitute an official endorsement or approval by the United States Department of Agriculture or the Agricultural Research Service of any product or service to the exclusion of others that may be suitable. 


\section{ACKNOWLEDGEMENT}

The author is grateful to Erin Walter for oxirane analyses.

\section{References}

1. Carothers, W.H.; Van Natta, F.J. Studies on polymerization and ring formation. III. Glycol esters of carbonic acid. J. Am. Chem. Soc. 52, 714- 326 (1930).

2. Choppin, A.R.; Rogers, J.W. The preparation of di-tbutyl carbonate and t-butyl chlorocarbonate. J. Am. Chem. Soc. 70, 2967-2968 (1948).

3. Shaikh, A.G.; Sivaram, S. Dialkyl and diaryl carbonates by carbonate interchange reaction with dimethyl carbonate. Ind.Eng. Chem. Res. 31, 1167-1170 (1992).

4. Shaikh, A.G.; Sivaram, S. Organic carbonates. Chem. Rev. 96, 951-976 (1996).

5. Peppel, W.J. Preparation and properties of the alkylene carbonates. Ind. Eng. Chem. 50, 767-770 (1958).

6. Ratzenhofer, M.; Kisch, H. Metal-catalyzed synthesis of cyclic carbonates from carbon dioxide and oxiranes. Angew. Chem. Int. Ed.Engl. 19, 317-318 (1980).

7. Nishakuba, T.; Kameyama, A.; Yamashita, J.; Tomoi, M.; Fukuda, W. Insoluble polystyrene-bound onium salt catalysts for the synthesis of cyclic carbonates by the reaction of oxiranes with carbon dioxide. J. Polym. Sci. Part A. 31, 939-947 (1993).
8. Vieville, C.; Yoo, J.W.; Pelet, S.; Mouloungui, Z. Synthesis of glycerol carbonate by direct carbonation of glycerol in supercritical $\mathrm{CO}_{2}$ in the presence of zeolites and ion exchange resins. Cat. Lett. 56, 245-247 (1998).

9. Sako, T.; Fukai,T.; Sahashi, R.; Sone,M.; Matsuno, M. Cycloaddition of oxirane group with carbon dioxide in the supercritical homogeneous state. Ind. Eng. Chem. 41, 5353-5358 (2002).

10. Dierker, M. Oleochemical carbonates - An overview, Lipid Tech. 16, 130 (2004).

11. Kenar, J.A.; Knothe, G.; Dunn, R.O.; Ryan, T.W.; Matheaus, A. Physical properties of oleochemical carbonates. J. Am Chem. Soc. 82, 201-205 (2005).

12. Khot, S.N.; Lascala, J.J.; Can, E.; Morye, S.S.; Williams, G.I.; Palmese, G.R.; Kusefoglu, S.H.; Wool, R.P. Development and application of triglyceride-based polymers and composites, J. Appl. Polym. Sci. 82, 703-723 (2001).

13. Tamami, B.; Sohn, S.; Wilkes, G.L. Incorporation of carbon dioxide into soybean oil and subsequent preparation and studies of nonisocyanate polyurethane networks. J. Appl. Polym. Sci. 92, 883-891 (2004).

14. Doll, K.M.; Erhan, S.Z. Synthesis of carbonated fatty methyl esters using supercritical carbon dioxide. $J$. Agric. Food Chem. 53, 9608-9614 (2005).

15. Oxirane value, AOCS Official Methods and Recommended Practices of the American Oil Chemists' Society. (AOCS, Champaign, IL) Cd9-57 (1998). 